\title{
Thrombolysis in acute myocardial infarction: the safety and efficiency of treatment in the accident and emergency department
}

\author{
J A Edhouse, M Sakr, J Wardrope, F P Morris
}

\begin{abstract}
Objectives-To assess the safety and efficiency with which the accident and emergency (A\&E) department provides thrombolytic treatment for patients with acute myocardial infarction (AMI).
\end{abstract}

Methods-A prospective observational study based in a teaching hospital for one year. All patients who presented with the clinical and electrocardiographic indications for thrombolytic treatment were studied. Patients were grouped according to route of admission. After logarithmic transformation, the "door to needle times" of the groups were compared using a two tailed Student's $t$ test. Arrhythmias and complications after thrombolytic treatment were noted. The appropriateness of the treatment was assessed retrospectively by review of the clinical records and electrocardiograms, judged against locally agreed eligibility criteria.

Results-Data from 153 patients were analysed; 138/153 (90\%) patients were admitted via the A\&E department. The shortest door to needle times were seen in those patients thrombolysed by A\&E staff within the A\&E department (mean 43.8 minutes). The transfer of $A \& E$ patients to the coronary care unit (CCU) was associated with a significant increase in the door to needle time (mean 58.8 minutes, $p=$ 0.004). Only one malignant arrhythmia occurred during the administration of thrombolysis in the A\&E department, and this was managed effectively. No arrhythmias occurred during transfer of thrombolysed patients to the CCU. In every case, the decision to administer thrombolysis was retrospectively judged to have been appropriate.

Accident and

Emergency

Department, Northern

General Hospital,

Herries Road,

Sheffield S5 7AU

$\mathrm{J}$ A Edhouse

M Sakr

J Wardrope

F P Morris

Correspondence to:

Miss Edhouse, Senior

Registrar in Accident and

Emergency Medicine

(e-mail:

junea@globalnet.co.uk).

Accepted 29 May 1999
Conclusions-The A\&E department provides appropriate, safe, and timely thrombolytic treatment for patients with AMI. Transferring A\&E patients to the CCU before thrombolysis is associated with an unnecessary treatment delay. (F Accid Emerg Med 1999;16:325-330)

Keywords: thrombolytic treatment; acute myocardial infarction

The benefits of thrombolytic treatment in AMI are well established, ${ }^{1-7}$ and the greatest benefits are seen in patients treated early. ${ }^{56}$ In view of the considerable benefit from early thrombolysis it has been recommended that thrombolytic treatment be given at the first opportunity, and with the same degree of urgency as the treatment of cardiac arrest. ${ }^{6}$ Guidelines have been published calling for hospitals to develop fast track systems that allow for the prompt identification of those with obvious myocardial infarction. $^{8}$

The interval between arrival at hospital and the start of treatment is known as the "door to needle time", and the audit standard for patients presenting with obvious indications for thrombolysis has been set at 30 minutes. $^{9}$ Duplication of medical assessment has been identified as a major factor causing in-hospital treatment delays. ${ }^{10}$ The shortest delays have been shown to occur when patients are thrombolysed within the accident and emergency (A\&E) department. ${ }^{11}{ }^{12}$ Nevertheless, a recent survey showed that only $35 \%$ of $A \& E$ departments give thrombolysis routinely. ${ }^{13}$

There may be a number of reasons why thrombolysis has not been widely adopted as a routine $A \& E$ procedure; there may be a lack of confidence in the ability of A\&E staff to interpret electrocardiograms (ECGs) correctly, resulting in the inappropriate use of thrombolytic treatment. There may be concerns regarding potential complications and reperfusion arrhythmias, particularly if these occur during transfer to the coronary care unit (CCU). A lack of space to accommodate patients undergoing thrombolysis and insufficient numbers of nursing staff to provide supervision may also be a problem for some departments.

In Sheffield, patients with suspected AMI may be admitted to hospital via the $A \& E$ department or by general practitioner referral directly to the medical admissions ward. During the study period, A\&E patients were thrombolysed immediately within the department, or after urgent transfer to the CCU. Patients admitted to the medical admissions ward were transferred to the CCU before thrombolysis.

The aim of the study was to assess whether the A\&E department could provide thrombolytic treatment in a safe, appropriate, and timely manner when compared with the other delivery options available within the hospital.

\section{Methods}

We performed a study in a teaching hospital in Sheffield for one year (1996-97). We studied all patients who on presentation fulfilled the eligibility criteria for thrombolytic treatment. A questionnaire was completed prospectively for patients thrombolysed by A\&E staff. The CCU 
Box 1: Electrocardiographic criteria for thrombolysis

1. ST elevation $>1 \mathrm{~mm}$ in two contiguous limb leads or $>2 \mathrm{~mm}$ in two contiguous chest leads.

2. Proved new left bundle branch block

3. Posterior myocardial infarction (tall $R$ wave V1, ST segment depression V2 and V3).

\section{Box 2: Contraindications to \\ thrombolytic treatment \\ Absolute contraindications}

Active gastrointestinal bleeding or active internal bleeding

Aortic dissection

Neurosurgery or head injury within two months

Cerebrovascular accident within two months

Intracranial aneurysm/neoplasm

Bleeding diathesis

Relative contraindications

Traumatic cardiopulmonary resuscitation

Proliferative diabetic retinopathy

Abdominal aortic aneurysm

Major surgery within 10 days

Uncontrollable hypertension (systolic blood pressure $>180 \mathrm{~mm} \mathrm{Hg}$ or diastolic blood pressure $>110 \mathrm{~mm} \mathrm{Hg}$ )

Gastrointestinal bleeding in previous six months or known ulcerative colitis

Subclavian puncture

Major trauma or childbirth within 10 days

and medical wards were visited daily in order to obtain data on all other patients. During the study period there was middle grade or consultant presence in the department for 13 hours a day (0800-2100 hours).

\section{THROMBOLYSIS ELIGIBILITY CRITERIA}

Patients were offered thrombolytic treatment if they presented within 12 hours of the onset of chest pain and fulfilled the required ECG criteria (box 1), provided there were no contraindications (box 2).

\section{HOSPITAL PROCEDURES}

Patients with suspected AMI received oxygen, aspirin, intravenous opiates, and antiemetics as appropriate.

The initial policy was to thrombolyse all suitable patients within the A\&E department.

Table 1 Demographic details of thrombolysis treatment groups

\begin{tabular}{llll}
\hline Treatment group & $\begin{array}{l}\text { No of } \\
\text { patients }\end{array}$ & $\begin{array}{l}\text { Mean age } \\
\text { (years) }\end{array}$ & $\begin{array}{l}\text { No (\%) presenting } \\
\text { "out of hours" }\end{array}$ \\
\hline Thrombolysis by A\&E staff in A\&E department & 56 & 66 & $30(53.5)$ \\
Thrombolysis by A\&E staff in CCU & 43 & 61 & $29(67)$ \\
A\&E patients referred for admitting team to thrombolyse & 29 & 64 & $20(69)$ \\
Patients "missed" by A\&E & 10 & 66 & $9(90)$ \\
Direct admission to medical ward & 13 & 71 & $10(77)$ \\
Thrombolysis inappropriately withheld & 2 & 65.5 & $2(100)$ \\
Total & 153 & & 100 \\
\hline
\end{tabular}

* “Out of hours" = time of arrival between $0000-0800$ hours weekdays, or during a weekend.
This took place in the resuscitation room, with continuous electrocardiographic monitoring. Transfer to the CCU occurred when a bed became available and was supervised by a doctor with a defibrillator. After a policy change, $A \& E$ patients were transferred to the CCU before thrombolysis if a bed was immediately available; the accompanying A\&E doctor started the infusion on the CCU. If the CCU could not offer immediate access to a bed, the thrombolytic infusion started in the A\&E department.

General practitioner referrals admitted directly to the medical admissions unit were transferred to the CCU before thrombolysis.

IDENTIFICATION OF PATIENTS ELIGIBLE FOR IMMEDIATE THROMBOLYSIS

All ECGs recorded before thrombolysis were obtained. The clinical records and ECGs were reviewed again after discharge, and patients with clear criteria for thrombolysis immediately on arrival were identified objectively, regardless of when they actually received thrombolysis.

Patients judged eligible for immediate thrombolysis were those with a clear history of chest pain, electrocardiographic criteria on their initial ECG, and no absolute or relative contraindications. We decided that the following patients could not reasonably be thrombolysed within the 30 minute target time; these patients were excluded from the analysis:

- Initial ECG did not fulfil eligibility criteria.

- Patients with history of recent infarct and ECG changes of indeterminate age.

- Relative contraindication or possible absolute contraindication.

- Atypical presentation.

- Difficulty obtaining clear history, for example severe dyspnoea.

- ECGs with left bundle branch block.

Cases in which thrombolysis was inappropriately given or withheld were subject to further blind review by an A\&E consultant and a cardiology consultant, who made the final decision.

\section{OUTCOME MEASURES}

- The door to needle times of the treatment groups. The door to needle time distribution was right skewed, and required logarithmic transformation before analysis with Student's two tailed $t$ test for samples with equal variance.

- Inappropriate administration of thrombolysis. The decision to give or withhold thrombolysis was judged appropriate or inappropriate according to locally agreed electrocardiographic and clinical criteria (see boxes 1 and 2).

- Patients in whom thrombolytic treatment was inappropriately withheld.

- The nature and management of arrhythmias occurring within two hours of thrombolysis.

- Complications occurring within 24 hours of thrombolysis. 


\begin{tabular}{lllll}
\hline & & \multicolumn{2}{c}{ Door to needle time (min) } \\
\cline { 3 - 5 } & No of patients & Mean & Median & Interquartile range \\
\hline Thrombolysis by A\&E staff in A\&E department & 56 & 43.1 & 42.5 & $28-51$ \\
Thrombolysis by A\&E staff in CCU & 43 & 58.8 & 54 & $40-71$ \\
A\&E patients referred for admitting team to thrombolyse & 29 & 94.2 & 82 & $55-118$ \\
Patients "missed" by A\&E & 10 & 234.5 & 201.5 & $138-239$ \\
Direct admissions to medical ward & 13 & 117.6 & 80 & $69-113$ \\
\hline
\end{tabular}

\section{Results}

Thrombolysis was administered to $220 \mathrm{pa}-$ tients presenting with suspected AMI, but only 155 of these patients had the clinical and electrocardiographic indications for thrombolysis immediately on arrival at hospital. Data collection was complete in $153 / 155(98.7 \%)$ of cases; this group of 153 patients was analysed in detail.

All patients had a straightforward mode of presentation, with clear indications for thrombolytic treatment; it was therefore appropriate to measure their door to needle times against the 30 minute standard. Other demographic data is summarised in table 1 .

Ninety per cent of patients were admitted via the $A \& E$ department. A\&E staff identified $92 \%$ of $A \& E$ patients requiring immediate thrombolysis, and administered thrombolysis to $72 \%$ of those eligible. Overall, $36 \%$ of $A \& E$ patients presented during periods when there was middle grade or consultant presence within the department.

TIME TO THROMBOLYTIC TREATMENT

The door to needle times are presented in table 2. The shortest door to needle times occurred when thrombolysis was given by $A \& E$ staff within the A\&E department. Transferring A\&E patients to the CCU before thrombolysis was associated with a significant increase in door to needle time, $p=0.004$. Direct

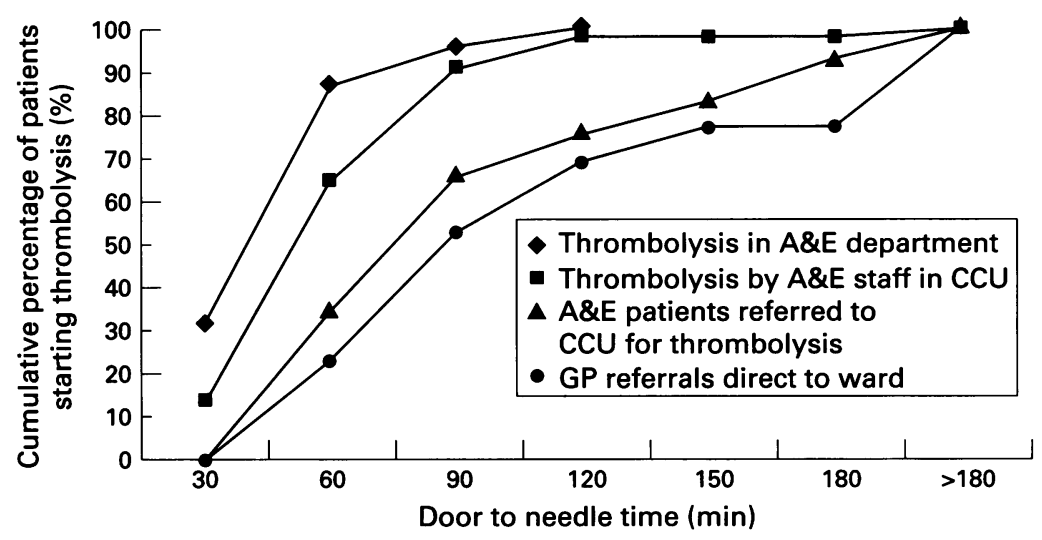

Figure 1 Proportion of patients starting thrombolysis within 30 minutes of arrival at hospital ( $G P=$ general practitioner).

Table 3 Complications of thrombolysis

\begin{tabular}{llll}
\hline Complication & Outcome & $\begin{array}{l}\text { Thrombolysis by } \\
\text { AEE staff }(n=99)\end{array}$ & $\begin{array}{l}\text { Thrombolysis by cardiology } \\
\text { staff }(n=52)\end{array}$ \\
\hline Minor haemorrhage & Complete recovery & 2 & 2 \\
Major haemorrhage & Complete recovery & 1 & 0 \\
Allergic reaction & Complete recovery & 5 & 1 \\
CVA & Residual problems & 0 & 3 \\
Transient hypotension & Complete recovery & 5 & 1 \\
Total & & 13 & 7 \\
\hline
\end{tabular}

CVA = cerebrovascular accident. admission to the medical admission unit was associated with the longest in-hospital treatment delays.

\section{ACHIEVEMENT OF AUDIT STANDARD}

When thrombolysis was given by $A \& E$ staff within the $A \& E$ department, $32 \%$ of patients received treatment within the target time of 30 minutes (fig 1), but when they were transferred to the CCU before thrombolysis, this proportion fell to $14 \%$. None of the $A \& E$ patients referred for thrombolysis by the senior house officer in cardiology received treatment within the 30 minute target time. Similarly, none of the patients admitted directly to the medical admissions unit started thrombolytic treatment within 30 minutes of arrival.

\section{ACCURACY OF ECG INTERPRETATION}

All thrombolytic administration was judged to have been given appropriately and in accordance with the clinical and electrocardiographic eligibility criteria.

A\&E staff failed to identify $10 / 139$ (7\%) patients who presented with obvious indications for thrombolysis, and six of these were subsequently assessed on multiple occasions by the admitting physicians before the ECG changes were recognised. These patients had very long door to needle times (mean 234.5 minutes) compared with other groups (see table 2).

\section{COMPLICATIONS OF THROMBOLYSIS}

Complications occurred in $13 \%$ of thrombolysed patients (table 3 ), and the proportion was similar in all groups. Transient hypotension and allergic reactions were the most common complications, both occurring in $4 \%$ of patients. The frequency of allergic reaction is comparable with other published rates of $4.4 \%{ }^{2}$ and $2.4 \% .{ }^{14}$ One patient developed anaphylactic symptoms, but in the majority of cases the allergic reaction was mild; the infusion was discontinued, and all patients responded to standard treatment with steroids and antihistamines. Transient hypotension responded to the temporary cessation of the thrombolytic infusion in all cases.

Bleeding occurred in $3.3 \%$ of patients, similar to other published figures. ${ }^{215} 16$ There were four cases of minor bleeding and one major gastrointestinal haemorrhage requiring blood transfusion.

Cerebrovascular accidents occurred in three $(1.9 \%)$ patients. Computed tomography was performed in two cases, and both demonstrated cerebral infarction. Thrombolysis trials have published stroke rates of $0.2 \%-1.04 \%,{ }^{215}$ 
Table 4 Reperfusion arrhythmias

\begin{tabular}{lllll}
\hline Arrhythmia & Treatment & Outcome & $\begin{array}{l}\text { Thrombolysis by } \\
\text { A E E staff } \\
(n=99)\end{array}$ & $\begin{array}{l}\text { Thrombolysis by } \\
\text { cardiology staff } \\
(n=52)\end{array}$ \\
\hline Sinus bradycardia & Atropine & Recovery & 9 & 3 \\
Ventricular fibrillation & DC shock & Recovery & 1 & 1 \\
Atrial fibrillation/flutter & Drugs & Recovery & 1 & 0 \\
Ventricular tachycardia & Drugs & Recovery & 1 & 0 \\
Complete heart block & Atropine/pacing & Recovery & 1 & 1 \\
Total & & & 13 & 5 \\
\hline
\end{tabular}

and in clinical practice in the UK a stroke rate of $2 \%$ has been described. ${ }^{16}$

\section{REPERFUSION ARRHYTHMIAS}

Arrhythmias that occurred during or within two hours of thrombolysis, and that required active treatment, were found in $11.9 \%$ of patients (table 4). Most commonly seen was a sinus bradycardia requiring a single dose of atropine.

Dangerous arrhythmias, for example ventricular fibrillation, sustained ventricular tachycardia, complete heart block or electromechanical dissociation, occurred in $3.3 \%$ of patients. There is no other strictly comparable published data, although the ISIS-2 study quotes a ventricular fibrillation rate of $3.3 \%$ and cardiac arrest rate of $7.2 \% .^{2}$

One life threatening arrhythmia (ventricular fibrillation) occurred in the A\&E department, and the patient recovered completely after DC cardioversion. No arrhythmias requiring treatment occurred during the transfer of thrombolysed patients to the CCU. Adverse events during the transfer of thrombolysed patients have been audited previously, ${ }^{16}$ and as in our study, no events were documented.

\section{Discussion}

The importance of early thrombolysis in patients suffering AMI is well established, and the causes of in-hospital treatment delay have been analysed. $.^{10-12} 16-20$ It has been demonstrated that thrombolysis within the $A \& E$ department is associated with the shortest treatment delays. ${ }^{101213}$ However, although most $A \& E$ consultants in the UK believe that thrombolysis should be given in A\&E, only 35\% of departments give thrombolytic treatment routinely. ${ }^{13}$

There may be a number of reasons why thrombolysis has not been widely adopted as a routine $A \& E$ procedure. These include concerns about the ability of $A \& E$ staff to interpret ECGs, or manage complications or arrhythmias, worries that patients may suffer reperfusion arrhythmias during transfer to the CCU, a lack of space to accommodate patients undergoing thrombolysis, and an insufficient number of nursing staff to provide supervision.

\section{IN-HOSPITAL TREATMENT DELAYS}

This study concurs with previous studies, ${ }^{10121316}$ which show that delays in the provision of thrombolytic treatment are significantly shorter when patients present to the A\&E department and are thrombolysed there. Although only $32 \%$ of patients thrombolysed in $A \& E$ were treated within the 30 minute tar- get time, prior transfer to the CCU is associated with an extremely low proportion of patients starting treatment within the target time (14\%).

Patients referred by general practitioners to the medical admissions unit experience much longer treatment delays than $A \& E$ patients; this may be due to a number of reasons. A preregistration house officer may perform the initial assessment. There may be delays waiting for ECG technicians to attend, and inexperienced doctors may fail to recognise ECG changes. Patients may be subjected to multiple medical assessments and incur further delay awaiting transfer to the CCU before thrombolysis.

PARAMEDIC DIRECT ACCESS TO CCU

Paramedic direct access to the CCU is considered by some to be the "gold standard" of care for patients with AMI. In a recent large study in which paramedics were trained to interpret ECGs and select patients for direct admission to the CCU, ${ }^{14}$ a mean in-hospital treatment delay of 39 minutes was achieved. However, fewer than $25 \%$ of all thrombolysed patients were admitted by this route. While direct paramedic access to the CCU may confer an advantage on a small selected group, it does not appear to be a practical option for reducing door to needle times for the majority of patients.

APPROPRIATENESS OF A\&E DEPARTMENT THROMBOLYSIS

There are reports in the literature raising doubts about the ability of $A \& E$ staff to interpret ECGs correctly, ${ }^{21-27}$ and this may partly explain why thrombolysis has not been widely adopted in A\&E departments. However, these studies compare the ability of $A \& E$ senior house officers with those of cardiology consultants, registrars, or staff grade doctors. The relevant comparison is surely between $\mathrm{A} \& \mathrm{E}$ and medical/cardiology junior staff; when this is studied there appears to be no difference in the number of clinically significant errors made. ${ }^{28}$

In our study, all thrombolytic treatment was administered appropriately and in accordance with locally agreed clinical and ECG eligibility criteria. There is no evidence that A\&E staff administer thrombolysis inappropriately. However, if the $A \& E$ department occasionally fails to identify patients with obvious indications for thrombolysis, very long door to needle times may result. The admitting physicians may assume that all candidates for thrombolysis have been selected out; A\&E staff must be aware of their responsibility to examine ECGs carefully and seek advice if they are in doubt.

SAFETY OF A\&E DEPARTMENT THROMBOLYSIS

Cardiac arrests are managed in most $A \& E$ departments on a daily basis, and $A \& E$ staff are therefore well practised in resuscitation techniques. Only one patient experienced a dangerous arrhythmia (ventricular fibrillation) in the $A \& E$ department, and this was managed effectively. 
The risk of arrhythmias occurring during the transfer of thrombolysed patients is sometimes cited as a reason to confine thrombolysis to the CCU. Our study, along with a previous study, ${ }^{16}$ demonstrates that this is a theoretical concern rather than a practical problem. If patients are transferred in the company of a doctor and a defibrillator, the risk is likely to be extremely small.

Transient hypotension and allergic reactions were the only complications that occurred in the $A \& E$ department. Complications are a recognised risk of thrombolytic treatment, and the emphasis must be on early detection and appropriate management.

\section{IMPLICATIONS OF PROVIDING THROMBOLYSIS IN THE A\&E DEPARTMENT}

Immediate assessment and ECG based triage

A high level of motivation is required among medical and nursing staff if patients are to be identified and thrombolysed with 30 minutes of arrival. Immediate assessment is essential in order to identify patients who may be infarcting. An ECG must be performed immediately and assessed by a member of the medical staff. Patients with the ECG criteria for thrombolysis are placed in the highest triage category and are seen immediately by a doctor.

\section{Training and guidelines}

In our study, $64 \%$ of patients requiring thrombolysis attended at times when there was no middle grade presence in the department. While the level of middle grade cover in $A \& E$ is increasing, it is still the case that senior house officers will see the majority of these patients. The education and training of senior house officers is therefore of paramount importance.

Training in the administration of thrombolysis must be given a high priority in the $A \& E$ induction programme, with emphasis on making an accurate diagnosis, checking carefully for contraindications, and most importantly, seeking senior advice when in doubt. The value of formal ECG training in reducing serious errors has previously been highlighted, ${ }^{23}$ and ongoing training and feedback are required.

Written clinical guidelines, dosage and administration information, and instructions regarding the management of complications, are vital if relatively inexperienced doctors are to administer thrombolysis confidently and safely. A contraindications checklist, completed for each patient, may be helpful as both an aide-mémoire and a permanent record.

\section{Role of experienced $A \mathcal{E} E$ staff}

The mortality benefit from early thrombolysis is considerable, and justifies the involvement of experienced $A \& E$ staff whenever possible, both to support senior house officers and facilitate the patient's management, just as they would in cases of major trauma or cardiac arrest. Departments lacking adequate staffing or facilities for training may not be in a position to provide safe and timely thrombolysis.

\section{Conclusions}

A\&E staff can accurately select the vast majority of patients who require thrombolysis for AMI. Significantly shorter in-hospital treatment delays are seen when thrombolysis is administered by $A \& E$ staff within the $A \& E$ department, when compared with other delivery options available within the hospital. The transfer of $A \& E$ patients to the CCU before thrombolysis is associated with an important and unnecessary treatment delay.

Every effort should be made to shorten treatment delays for patients with AMI. The $\mathrm{A} \& \mathrm{E}$ department is best placed to deliver timely thrombolytic treatment. Where local facilities and conditions allow, A\&E departments should develop the necessary education and training programmes in order to ensure the provision of safe and timely thrombolytic treatment for patients with AMI. The authors would like to acknowledge the assistance of the
audit department of the Northern General Hospital and the audit department of the Northern General Hospital and the all the consultant cardiologists and physicians of the Northern General Hospital.

Conflict of interest: none.

Funding: M Sakr was supported by Sheffield Health Authority.

1 Gruppo italiano per lo Studio della Streptochinasi nell'Infarcto miocardio (GISSI). Effectiveness of intravenous thrombolytic treatment in acute myocardial infarcvenous thrombolytic treatment
tion. Lancet 1986;i:397-402.

2 ISIS-2 (Second International Study of Infarct Survival) Collaborative Group. Randomised trial of intravenous streptokinase, oral aspirin, both, or neither among 17187 cases of suspected acute myocardial infarction: ISIS-2. Lancet 1988;ii:349-59.

3 Wilcox RG, Olsson CG, Skene AM, et al for the ASSET (Anglo-Scandinavian Study of Early Thrombolysis) Study Group. Trial of tissue plasminogen activator for mortality reduction in acute myocardial infarction (ASSET). Lancet 1988;ii:525-30.

4 The GUSTO investigators. An international randomized trial comparing four thrombolytic strategies for acute myocardial infarction. N Engl $\mathcal{Y}$ Med 1993;329:673-82.

5 Fibrinolytic Therapy Trialists' Collaborative Group. Indications for fibrinolytic therapy in suspected acute myocardial infarction: collaborative overview of early mortality and major morbidity results from all randomised trials of more major morbidity results from all randomised

6 Rawles J. Magnitude of the benefit from earlier thrombolytic treatment in acute myocardial infarction: new evidence treatment in acute myocardial infarction: new evidence
from Grampian region early anistreplase trial (GREAT). from Grampian region

7 Baigent C, Collins R, Appleby S, et al on behalf of the ISIS-2 Collaborative Group. ISIS-2: 10 year survival among patients with suspected acute myocardial infarction in randomised comparison of intravenous streptokinase, oral aspirin, both, or neither. $B M \mathcal{F} 1998 ; 316: 1337-43$.

8 Weston CFM, Penny WJ, Julian DG on behalf of the British Heart Foundation Working Group. Guidelines for the early management of patients with myocardial infarction. $B M^{\mathcal{F}}$ 1994;308:767-71.

9 De Bono DP, Hopkins A. The management of acute myocardial infarction: guidelines and audit standards. Joint Audit Committee of the British Cardiac Society and the Cardiac Society, 1996.

10 Gonzalez ER, Jones LA, Ornato JP, et al. Hospital delays and problems with thrombolytic administration in patients receiving thrombolytic therapy: a multicenter prospective receiving thrombolytic therapy: a multicenter

11 More R, Moore K, Quinn E, et al. Delay times in the administration of thrombolytic therapy: the Brighton experience. Int $\mathcal{F}$ Cardiol 1995;49:S39-46.

12 Birkhead J, on behalf of the joint audit committee of the British Cardiac Society and a cardiology committee of the Royal College of Physicians of London. Time delays in provision of thrombolytic treatment in six district hospitals. BMF 1992;305:445-8.

13 Hood S, Birnie D, Swan L, et al. Questionnaire survey of thrombolytic treatment in accident and emergency departments in the United Kingdom. BMF 1998;316:274.

14 Sandler DA. Paramedic direct admission of heart-attack patients to a coronary-care unit. Lancet 1998;352:1198.

15 ISIS-3 (Third international study of infarct survival) collaborative group. ISIS-3: a randomised comparison of streptokinase vs tissue plasminogen activator vs anistreplase and of aspirin plus heparin vs aspirin alone among 41299 cases of suspected acute myocardial infarction. Lancet 1992;339:753-70. 
16 Nee P, Gray A. Audit of thrombolysis initiated in an accident and emergency department. Quality in Health Care 1994;2:29-33.

17 Eisenberg $M$. Reducing the door-to-drug interval for thrombolytic therapy. Acad Emerg Med 1995;2:579-80.

18 Pell ACH, Miller HC. Effect of "fast-track" admission for acute myocardial infarction on delay to thrombolysis. $B M F$ 1992;304:83-7.

19 Pell ACH. Delays in admission of patients with acute myocardial infarction to coronary care: implications for thrombolysis. Health Bulletin 1990;48/5 (September).

20 Porter G, Doughty R. Thrombolysis in acute myocardial infarction: reducing inhospital treatment delay. $N Z$ Med $\mathscr{f}$ 1995;108:253-4.

21 Snoey ER, Housset B, Guyon P, et al. Analysis of emergency department interpretation of electrocardiograms. F Accid Emerg Med 1994;11:149-53.

22 McCallion WA, Templeton PA, McKinney LA. Missed myocardial ischaemia in the accident and emergency department: ECG. A need for audit? Arch Emerg Med 1991;8:102-7.
23 White $T$, Woodmansey $P$, Ferguson $D$, et al. Improving the interpretation of electrocardiographs in an accident and emergency department. Postgrad Med $\mathcal{f} 1995 ; 71: 132-5$.

24 Morrison WG, Swann IJ. Electrocardiograph interpretation by junior doctors. Arch Emerg Med 1990;7:108-10.

25 Emerson PA, Russell NJ, Wyatt J, et al. An audit of doctor's management of patients with chest pain in the accident and emergency department. $Q \mathcal{F}$ Med 1989;70:213-20.

26 Gjorup $T$, Kelbaek H, Nielsen $D$, et al. Interpretation of the electrocardiogram in suspected myocardial infarction: a electrocardiogram in suspected myocardial infarction: randomised controlled study of the effect of a training programme to reduce interobserver variation. Fournal of Inter-
nal Medicine 1992;231:407-12.

27 Westorp EJ, Gratton MC, Watson WA. Emergency department interpretation of electrocardiograms. Ann Emerg Med 1992;21:541-4.

28 Dudley M, Channer KS. Assessment of the value of technician reporting of electrocardiographs in an accident and emergency department. $f$ Accid Emerg Med 1997;14:30710. 